\title{
ROOT CANAL MICROFLORA
}

\author{
Marina George, Romana Ivančaková \\ Charles University in Prague, Faculty of Medicine in Hradec Králové and University Hospital Hradec Králové, \\ Czech Republic: Department of Dentistry
}

Summary: Modern day endodontics is undergoing a massive change with the introduction of new molecular based techniques for microbial identification. This review focuses on the microbiota in untreated and root-filled canals. It will also describe briefly the recent developments in microbial identification and the mechanisms by which certain species of microbes are able to invade and establish themselves in the root canal.

Key words: Microbiota; Molecular methods; Pathogen; Microbial symbiosis

\section{Introduction}

The literature on the role of microorganisms in root canal infection has an interesting historical background in view of the pathbreaking molecular techniques which have shed new light on our present knowledge of oral microbiology. The Chinese believed that a white worm with a black head lived in the tooth and it caused abscesses (19). The worm theory which was followed until the middle of $18^{\text {th }}$ century, and thereafter the hollow tube theory (74), prevented the pursuit of a bacterial cause for pulpal disease. Although van Leeuwenhoek in the $17^{\text {th }}$ century described the presence of microorganisms in the root canal of a badly carious tooth (6), it was not until the end of $19^{\text {th }}$ century that his findings were corroborated by W.D.Miller. In 1894, Miller published his findings on the bacteriological investigation of root canal infection (49). This was followed by systematic culturing of root canals and in the 1930's microbiological techniques were used to determine the biological basis of endodontic methods. However, the recovery of Gram positive facultative bacteria led to confusing clinical reports and these came to be regarded as endodontic pathogens. In the 1960's, with the development of anaerobic culturing, many unknown microorganisms were identified in the root canal and it came to be believed that endodontic microbiota were predominantly anaerobes. Moller's thesis on the importance of adequate isolation for root canal samples and anaerobic culture techniques established new guidelines in endodontic microbiology. Sundqvist's thesis in 1976 was a major turning point in endodontics, since the taxonomy finally confirmed the role of anaerobes in endodontic infection. Subsequently, the pathogenecity and the presence of black pigmented Gram negatives were studied along with a diverse number of other Gram negati- ves. With the advent of a medium of transport like VMGA III and use of modern molecular assays, there has been a manifold increase in the identification of new species and species which are difficult to culture.

\section{Oral and root canal microflora}

Miller was the first who described the presence of a characteristic root canal microbiota. He observed that there was a difference in the bacteria in the teeth with open pulp chambers and those in the root canals. It was also observed that only some were cultivable when compared to the numerous microbes seen under the microscope, and that the flora in the coronal, middle and apical parts of the root canal differed. The variation in the nutrient and oxygen tension in the apical region compared to that in the main canal are the causative factors for the presence of slow growing, obligate anaerobes at the apical site (102). However, the limitations in his sampling and cultivation technique hampered the verification of the observation (26).

The resident microbial flora in the oral cavity typically contains $10^{10}$ bacteria (50). Over 500 bacterial species are today recognized as normal inhabitants of the oral cavity $(57,73)$. However, only 150 microbial species have been isolated and cultured from root canals. The endodontium is a sterile cavity and the ingress of oral microbes to establish infection is quite difficult when compared to other dental tissues, as the microorganisms have to penetrate the enamel and dentine and overcome the host responses. Furthermore, they have to survive in the limited space, nutrients and distinct habitat alongside other root canal microorganisms by genetic exchange, mutation and highly modified functions (5). Therefore, although all the bacteria in the oral cavity can invade the root canal, only a few microbes 
have been identified in infected root canals $(42,49,96,98$, 111).

\section{Endodontic pathogens and microbial symbiosis}

A classic study by Kakehashi and co-workers in the 1960's demonstrated the role of infection in the demise of damaged pulps and this paved the way for a scientific basis for clinical studies. The study proved that pulp necrosis and periapical bone destruction occurred in both germ-free and non-germ-free rats when the pulp chambers were kept open to the oral cavity (40). An estimated 2-10 different species, total numbers varying between $10^{3}$ to $10^{7}$, are found in infected canals (8). It has also been seen that teeth with large long standing periapical infections contain very dense and more bacterial species in their root canals than in smaller periapical lesion (102).

The interrelationships between microbes in the disease process have been positively established by the studies of Fabricius et al. (26) on monkeys, experiments on the role of Prevotella intermedia and Porphyromonas endodontalis in abscess formation and transmission in Guinea pigs (101) and later by the studies of Winkelhoff et al. (105). In the studies of Fabricius et al., bacterial isolates from the root canal of a monkey were inoculated as separate or combined strains into the root canals of other monkeys. The study revealed that the separate strains produced only a small lesion and mild periapical reaction in comparison to the combined strains. Similar experiments involving $P$. oralis revealed that it did not survive as a single isolate. However, the presence of other bacteria seemed to favour its survival and dominance within the root canal. Enterococcus faecalis and Streptococcus milleri were also found to induce weak periapical reactions when inoculated as separate strains, although they could survive in the root canal as single isolates.

The synergistic mechanisms between the various endodontic pathogens involve an interplay of various factors, like providing nutrition, inhibition of phagocytosis (i.e. preventing opsonisation and inflammation, destruction of phagocyte), secretion of growth factors and enzymes, decrease in the local oxygen concentration and oxidation-reduction potential and local $\mathrm{pH}$ in the root canal. These mechanisms facilitate the survival and pathogenesis of obligate and facultative anaerobes (98).

\section{Portal of entry of microorganisms}

The dentine-pulp complex is normally protected from the microbial invasion by the intact enamel and cementum. The ingress of invading bacteria occurs when there is a break in the integrity of the overlying enamel and dentine by caries, trauma, and contamination of the pulp during dental treatment (including root canal treatment), seepage of saliva through cracks or inadequate coronal restorations (74). The bacteria of the carious process advances ahead when the infecting pathogen enters through caries. When there is trauma without pulp exposure, the access of the bacteria is through the dentinal tubules. However, little is known about the pattern of the primary invading microorganisms (96, 98). With the establishment of infection, the microbial flora changes from an initially predominant facultative Gram positive flora to a completely anaerobic Gram negative bacteria when the canals have been infected for 3 months or more (26).

\section{Factors determining the composition of the microbiota}

The biological environment within the root canal space is highly varied as the space and nutrient availability is limited and the microorganisms have to compete with each other to establish themselves under the unfavourable conditions. The relative proportion of the endodontic milieu is determined by environmental conditions.

Experiments in which bacterial strains originally isolated from an infected root canal were inoculated in equal quantity into further canals re-established the original proportion of bacterial strain with a predominance of anaerobes. It has been observed that Prevotella oralis (formerly Bacteroides oralis) are more likely to survive and dominate the flora in combination with other bacteria than when they are an inocula of a single species (25). These experiments point out that specific interactions between the anaerobes, oxygen consumption and production of carbon dioxide and hydrogen, with the resulting reduction-oxidation potential, establish the relative proportion among the micro-organisms and result in an increase in the proportion of anaerobes.

\section{Microbial ecology in the infected root canal}

There are several ecological factors which determine the survival of root canal microflora. The presence of bacterial synergy is responsible for the presence of several root canal microorganisms. Odds ratios, which is used to determine one species in the presence or absence of another species, helps to analyse the microbial inter-relationships (95). A positive association was found between Fusobacterium nucleatum and $P$. micros, $P$. endodontalis, $C$. rectus, and Selenomonas sputigena. Similar inter-relationships were observed between $P$. intermedia and $P$. micros, $P$. anaerobius, and Eubacterium species. Eubacteria was associated with Peptostreptococcus while P. endodontalis was associated with Fusobacterium nucleatum, Eubacterium alactolyticum, and $C$. rectus. However $P$. endodontalis was negatively associated with $P$. intermedia. A facultative streptococcus was not associated with other bacteria. Propionibacterium propionicum, Capnocytophaga ochracea, and Veillonella parvula and other species were found to be negatively associated with other bacteria (98).

The nutritional demands of one species is met by the metabolism of the other species due to this peculiar bacte- 
rial association. The coronal parts of the exposed root canal, having exogenous nutrients (carbohydrates), and the body of the root canal, with endogenous nutrients (proteins, glycoproteins), influence microbial ecology.

Scanning electron microscopic studies by Siqueira et al. revealed the presence of cocci, rods and fungi in mixed communities colonizing the root canal walls, penetrating the dentine tubules up to approximately $300 \mu \mathrm{m}$. The presence of a climax community in primary root canal infection helps in the disease progression of polymicrobial infection within the canal and in the formation of periapical lesions (86). Mechanisms for biofilm formation may be found in infected root canals. However, the concept of biofilm formation in endodontics is not clear and there is no strong evidence as to the presence of biofilms in infected root canals (104).

\section{Root canal sampling and cultivation}

Isolation and cultivation techniques play an important role in the identification of root canal microbiota. The confusion in the results of the earlier microbial studies were mainly due to the use of broth for preliminary cultivation of the sample, resulting in the isolation of mainly the fastgrowing bacteria. Furthermore, the hydrogen peroxide and superoxide radicals formed in the broth media during autoclaving caused lysis of the anaerobic bacteria. Also, the oxygen sensitive bacteria could not be cultivated using earlier bacteriologic techniques until the strict protocol for anaerobic culture was developed by Moller $(98,102)$.

Studies on the bacteriology of the necrotic pulp of human teeth devitalized by trauma showed that no bacteria could be isolated from teeth without apical periodontitis, while bacteria were always isolated from the teeth with apical periodontitis. The pioneering studies by Kakehasi et al. (40) and experimental studies in monkeys established the bacterial etiology in apical periodontitis and proved false the idea that the necrotic pulp, alongwith stagnated tissue fluid in the root canal, can result in apical periodontitis.

The VPI method by the Virginia Polytechnic Institute, a simplified version of the method developed by Hungate, revealed that obligate anaerobes predominate in infected root canals and play a major role in the development of apical periodontitis $(96,102,111)$. P. anaerobius, $P$. endodontalis and Fusobacterium species are considered to be highly oxygen sensitive. Anaerobic bacteriological techniques like the VPI method and anaerobic glove box and media containing haemolyzed blood have a protective effect on the anaerobic bacteria (102).

Dilution of samples and their cultivation on solid media allows for the growth of different species and their identification as single colonies. Root canal infection usually reveals 20-30 genera. However, culture-based techniques reveal only 4-12 taxa per root canal $(3,97)$. In the 1990's, Kary Mullis described the PCR (polymerase chain reaction) and it was a breakthrough in the field of endodontic microbio- $\operatorname{logy}(58)$. This method uses a DNA polymerase enzyme to make multiple copies of any given part of DNA or gene, thereby facilitating a large number of other molecular biology applications (70). It also enables quick and easy identification of numerous isolates, and the technique is easily learned. For example, 16S rRNA sequence analysis revealed 20 taxa at an average of 12.6 per sample in a study on 261 isolates from 5 infected root isolates (60). There are several drawbacks to this method: 1) even an unexperienced microbiologist can do this technique leading to wrong identification of microbes, 2) data interpretation is difficult, and 3 ) closely related groups are difficult to differentiate. In endodontics, taxa which are difficult to separate, are the mitis group of streptococci ( $S$. mitis, S. oralis, S. sanguis, and $S$. gordonii), Actinomyces species, (A. gerencseriae, $A$. israelii, A. meyeri, A. naeslundii, A. odontolyticus, A. viscosus, A. radicidentis) and coagulase-negative staphylococci ( $S$. epidermidis, $S$. warneri, $S$. lentus etc) and Veillonella species ( $V$. parvula, $V$. atypica and $V$. dispar). Presently this problem has been overcome by identifying them using genes like manganese-dependant superoxide dismutase ( $\operatorname{sod}$ A) (94).

Real-time PCR or quantitative PCR uses fluorescence to detect PCR products, thereby identifying and quantifying specific taxa (99). Checkerboard DNA-DNA hybridization introduced by Sigmund Socransky uses whole genomic DNA for 40 bacterial taxa and 28 patient samples per membrane, thereby allowing faster detection $(35,92$, $93,105)$. The disadvantage with this method is unknown cross reactivity with unknown taxa in the culturable taxa (94). This has not been increasingly used in endodontics.

The subtractive PCR cloning approach is used to determine the unculturale microbiota. In a study by Munson et al. (60) using culture and cloning method, 65 taxa of which 27 were novel were found in 5 root canal samples. However the disadvantages inherent in this technique are that it is costly, needs more time and the universal primers are not exactly universal in nature as previously regarded (75, 79).

Whole community analysis comprises of defining the community and its characteristics as a whole from a root canal and comparing these characteristics with other root canals. DGGE (denaturing gradient gel electrophoresis) is an example of this technique. It separates DNA fragments based on their sequence information (62) using the electrophoretic mobility of partially denatured DNA molecules in a polyacrylamide gel, which is encumbered in comparison with a completely helical form of the molecule (61). Using this method, Siqueira et al. (88) have shown different band patterns between symptomatic (12 taxa) and asymptomatic ( 7 taxa) root canal infection. Gram-negative anaerobes comprised of less than $20 \%$ of the microbes recovered in the study by Chávez et al. (10). Nearly $50 \%$ of the oral microbiota are yet to be identified by conventional culture techniques.(Wilson MJ,) However, there is no clear data available on the percentage of uncultivable gram negative anaerobes. 
Thus traditional culture methods and molecular based techniques need to be coupled effectively to isolate the endodontic microflora and classify the novel taxa for a thorough understanding of etiological factors in root canl infection.

\section{Classification of root canal flora}

With recent advances in molecular biological methods, the endodontic microflora is being continually reclassified. Molecular biological methods like PCR have enabled amplification of small amounts of nucleic acids and allowed for identification of bacteria that would be detectable by culturing techniques. PCR only complements data obtained from other methods, as it does not detect every organism as detected by culturing.A systematic classification of the endodontic milieu is of utmost importance to correlate data from various clinical studies. The black-pigmented bacteria have been reclassified from the earlier single species of Bacteroides melaninogenicus to 8 different species of blackpigmented anaerobic bacteria. The black-pigmented saccharolytic species have been reclassified into the new genus Prevotella and the asaccharolytic species into the new genus Porphyromonas. The eubacterium genus was formerly classified as E. lentum and Eubacterium group 4. Using molecular methods E. lentum has been reclassified as Eubacterium exiguum and later Slackia exigua. Eubacterium group 4 was

Tab. 1: Nomenclature of endodontic flora.

\begin{tabular}{|c|c|}
\hline Present Designation & Former Designation \\
\hline \multicolumn{2}{|c|}{ Oral black-pigmented Gram negative anaerobes (10) } \\
\hline $\begin{array}{l}\text { Porphyromonas } \\
\text { asaccharolytica }\end{array}$ & $\begin{array}{l}\text { Bacteroides } \\
\text { asaccharolyticus }\end{array}$ \\
\hline P. endodontalis & B. endodontalis \\
\hline$P$. gingivalis & B. gingivalis \\
\hline Prevotella intermedia & B. intermedius \\
\hline P. nigrescens & B. intermedius \\
\hline P. melaninogenica & B. melaninogenicus \\
\hline P. denticola & B. denticola \\
\hline P. loescheii & B. loescheii \\
\hline Tissierella praeacuta & Bacteroides praeacutus \\
\hline $\begin{array}{l}\begin{array}{l}\text { Propionibacterium } \\
\text { propionicum }\end{array} \\
\end{array}$ & Arachnia propionica \\
\hline \multicolumn{2}{|c|}{ Non fermentive anaerobes } \\
\hline Dialister pneumosintes & Bacteroides pneumosintes \\
\hline Filifactor alocis & Fusobacterium alocis \\
\hline \multicolumn{2}{|c|}{ Gram negative anaerobes } \\
\hline Tanerella forsythensis (32) & Bacteroides forsythus \\
\hline Streptococcus anginosus (48) & Streptococcus milleri \\
\hline $\begin{array}{l}\text { Actinomyces gerencseriae } \\
\text { (102) }\end{array}$ & $\begin{array}{l}\text { Actinomyces israelii } \\
\text { serotype II }\end{array}$ \\
\hline
\end{tabular}

Adapted from Sundqvist, 1994 classified as E. timidum which later included the new species and genus Mogibacterium neglectum, M. timidum, $M$. vescum, M. pumilum and Cryptobacterium curtum (98). Campylobacter rectus and $C$. curvus were classified as Wolinella recta and $W$. curva. Arachnia propionica, which belonged to genus Arachnia, is now included in the genus Propionibacterium as $P$. propionicum.

The predominantly isolated bacteria in the root canal, namely Fusobacterium nucleatum, comprises three subspecies - nucleatum, polymorphum and vincentii. The majority of the Streptococcus species included S. anginosus and S. mitis. Peptostreptococcus micros and P. anaerobius comprised of $1 / 3$ of the samples in the study by Sundqvist, while $34 \%$ of the root canals comprised of black-pigmented anaerobic rods, mainly Prevotella intermedia, and $6 \%$ constituted $P$. loescheii and $P$. denticola. Porphyromonas endodontalis was more predominant than $P$. gingivalis among the black-pigmented asaccharolytic species. Eubacterium alactolyticum and E. lentum were isolated in $1 / 3$ of the root canals.

Actinomyces species comprised $15 \%$ of the microflora and the dominant species was A. israelii (11\%). Similar results were reported in other studies examining teeth with necrotic pulps. Actinomyces israelii has been found to be commonly associated with root canal failures. Gram negative asaccaharolytic rods were identified as Fusobacterium and Bacteroides when butyric acid and acetic acid or succinic acid, respectively, was formed during fermentation.

Tab. 2: Bacteria isolated from root canals of teeth.

\begin{tabular}{|l|l|}
\hline Gram positive cocci & Gram negative cocci \\
\hline Streptococcus anginosus & Capnocytophaga ochracea \\
\hline S. gordonii & C. sputigena \\
\hline S. oralis & Veillonella parvula \\
\hline S. mitis & Campylobacter rectus \\
\hline S. sanguinis & C. curvus \\
\hline Enterococcus faecalis & \\
\hline Peptostreptococcus micros & \\
\hline Peptostreptococus anaerobius & \\
\hline Gram positive Rods & Gram negative Rods \\
\hline Actinomyces israelii & Fusobacterium nucleatum \\
\hline A. naeslundii & \\
\hline & Prevotella intermedia \\
\hline Eubacterium alactolyticum & Prevotella melaninogenica \\
\hline Eubacterium lentum & Prevotella denticola \\
\hline Eubacterium timidum & Prevotella buccae \\
\hline Eubacterium brachy & Prevotella buccalis \\
\hline Eubacterium nodatum & Prevotella oralis \\
\hline & Prevotella loescheii \\
\hline Propionibact. propionicum & \\
\hline P. granulosum & Porphyromonas gingivalis \\
\hline & Porphyromonas endodontalis \\
\hline Lactobacillus & \\
\hline & Bacteroides gracilis \\
\hline
\end{tabular}

Adapted from Sundqvist, 1992 a, b, 1994; Le Goff et al, 1997, R. M. Love, H. F. Jenkinson, 2002 
Since these species show few differentiating features, their characteristics can be established using polyacrylamide gel electrophoresis (98). Gram positive anaerobic rods which grew in broth containing polysorbate 80 were found by polyacrylamide gel electrophoresis to be similar to strains of Lactobacillus D2 and D10 (Moore et al.).

Numerous other anaerobic species which have been isolated are Porphyromonas asaccaharolytica, Prevotella melaninogenica, P. bivia, P. oulora, Tissierella praeacuta, Bacteroides fragilis, Bifidobacterium adolescentis, Clostridium clostridiforme, Peptostreptococcus productus, P. parvulus, P. asaccharolyticus, P. magnus, Eubacterium tenue, E. combesi, E. saburreum, E. limosum, E. aerofaciens, Fusobacterium varium, F. mortiferum, F. naviforme, Lactobacillus cellobiosus, $L$. casei subspecies rhamnosus, L. crispatus, L. fermentum, $L$. plantarum, and Mitsoukella dentalis. Enterobacter agglomerans, Staphylococcus epidermidis, S. aureus, and Bacillus, Acinetobacter, and Corynebacterium species and spirochetes have also been found in the canals (98). PCR has enabled the identification of previously difficult to culture species like Dialister pneumosintes (66\%) and Filifactor alocis in (46\%) root canals of teeth with apical periodontitis.

Thus the endodontic flora has predominantly gram negative anaerobes but gram positive facultatives are also seen. However, aerobic bacteria like Pseudomonas aeruginosa are found only when they enter the canal during the treatment. The most frequently isolated species from infected root canal are the black -pigmented bacteria. They are closely associated with clinical symptoms like pain, tenderness on percussion and swelling (33). Enterococcus and streptococcus have been found in teeth with endodontic failure (33), whereas Actinomyces species predominate in teeth with persistent periapical lesions (41). Candida has been detected mostly in teeth with persistent apical periodontitis $(53,103)$ while spirochetes are associated with endodontic abscesses(29). Propionibacterium propionicum are also related to persistent root canal infection (89). However, the role of lactobacillus in endodontic infection is unclear.

\section{Black-pigmented bacteria}

Black-pigmented bacteria are gram negative anaerobes commonly seen in infected root canals and endodontic abscess $(34,39,100,101,106)$. Their pathogenicity is due to the presence of fimbriae, capsules, outer membrane proteins and endotoxic lipopolysaccharides. They have been found in frequencies of $13 \%$ of the root canals by culture and in $50 \%$ by PCR screening methods (31). P. nigrescens has been more commonly found than $P$. intermedia in root canal infections. Both have been found in $26-40 \%$ of root canals of teeth with apical periodontitis $(45,95,109)$, while another PCR study revealed only $13 \%$ of these species (87). Culture studies of $P$. endodontalis and $P$. gingivalis has revealed only $10 \%$ of these isolates. However, Gomes et al. reported the predominance of $P$. gingivalis (38\%), followed by $P$. endodontalis (25\%), and P. nigrescens (22\%) (31).
Similar results were reported by Siqueira et al. (87) in endodontic exudates. $P$. intermedia were reclassified as $P$. nigrescens and these can be differentiated using sodium dodecyl sulfate-polyacrylamide gel electrophoresis and PCR based tests, which have shown $P$. nigrescens to be more frequently found than $P$. intermedia in root canal infections (2). Prevotella tannerae were previously classified as non-pigmenting saccharolytic Prevotella species, as they inconsistently produced black-pigment but it is now included in the BPB-group (56). This species was recovered in $60 \%$ of the cases with abscesses or cellulitis of endodontic origin.

\section{Spirochetes}

Oral spirochetes have been associated with abscesses of endodontic origin. Spirochetes have been identified using microbiological methods, dark-field microscopy and transmission electron microscopy, and more recently with molecular studies. Treponema denticola and T. socranskii are more frequently isolated from endodontic infection while T. lecithinolyticum and T. maltophilum are recovered less frequently. However, T. amylovorum, T. medium, T. pectinovorum and $T$. vincentii are rarely found in the root canals. $T$. denticola was found in $13 \%$ and $78 \%$ of the cases. T. denticola were obtained in $75 \%$ of cases with odontogenic swelling in a study by Foschi et al. (29). Certain studies have put forward the hypothesis that $T$. denticola may be associated with osteoclastogenesis by virtue of their virulence factors in root canal infections $(14,27)$. There is also a hypothesis regarding the role of $T$. denticola in endodontic and periodontic infection and the formation of atheromatous plaques (9). Tanerella forsythensis grows in the presence of other bacteria and has not been cultured from root canals (115). It belongs to the 'red complex' group of periodontal pathogens (115). PCR studies have revealed its presence in $18 \%$ of root canals (17).

\section{Enterococcus}

The enterococci are relatively uncommon in primary endodontic infection, while in secondary endodontic infection $29-77 \%$ comprised these microbes. This disparity in occurance has been attributed to post-endodontic coronal leakage, iatrogenic cause (i.e. inclusion during the endodontic procedure) or by leaving the root canal open to the oral environment (85). Another explanation is that E. faecalis may be present in undetectable levels in the untreated root canal and outcompeted by other endodontic microbes, but under favourable conditions may become highly prevalent. This was evident in a study where Enterococcus was isolated after using various intra-canal dressings like calcium hydroxide (72,78), clindamycin, $5 \%$ IKI $(20,52,55,85)$, tetracycline, and erythromycin (51). The pathogenecity exhibited by these species may be due to the presence of secreted factors e.g. toxic cytolysin and gelatinase (48), adhesins (e.g. aggregation substance, enterococcal surface 
protein, collagen adhesin) $(64,69,77,82,84)$, surface structures like capsular polysaccharide (38), sex pheromones (83), and extracellular superoxide production. The presence of potential adaptive mechanisms was demonstrated by Fabricius in his study on E. faecalis in devitalized pulps (24).

Enterococcus is known to acquire antibiotic resistance genes from other microbes or by spontaneous mutation, thereby making these microbes recalcitrant to the usual root canal medicaments and treatment (59). The presence of serine protease and collagen binding protein help in the invasion of E. faecalis into the dentinal tubules (37). E. faecalis is also known to posses alkaline tolerance due to cell-wallassociated proton pump (24). A study in Lithuania (Peciuliene et al. 2000) where calcium hydroxide is not used as an root canal medicament revealed that yeasts and enteric bacteria showed no particular material preference, and their presence was due to the favourable environment in the poorly root filled teeth rather than due to calcium hydroxide resistance.As $E$. faecalis can withstand long-term starvation, it may be possible to endure starvation in the root canal and when there is access to periapical tissue transudate like serum or serum-like fluid a few cells may survive, leading to persistence of the periapical lesion.

\section{Streptococcus}

Streptococci have been isolated in a large proportion of cases with primary endodontic infection $(5,54,96)$, during endodontic treatment $(11,32)$ and in retreatment cases $(17$, 53,103 ). They constitute approximately $20 \%$ (i.e. $16-50 \%$ ) of the endodontic mileu in post-treatment cases (102). Oral streptococci involve 4 groups (102) and commonly belonged to the Streptococcus mitis and S. anginosus groups of which $S$. gordonii, $S$. anginosus, and $S$. oralis were most frequently isolated $(11,12,13)$. The Streptococcus anginosus group includes $S$. intermedius and $S$. constellatus. These microbes are known to penetrate dentinal tubules separately and as co-aggregates (46). Their survival in the root canal is due to their adaptive response to extreme environmental change. The pathogenicity of $S$. anginosus in root canal infection may be due to its mechanism for attachment and co-aggregation, which is responsible for its presence in micro-communities (10). The pathogenesis of $S$. gordonii in apical periodontitis is not documented but it is known to help in the co-adhesion of Porphyromonas gingivalis to dental plaque $(15,66,44)$ and its invasion into dentinal tubules (47). Biofilm formation is also found to be dependent on the intracellular transport of manganese in $S$. gordonii $(18,22)$. Biofilm formation by streptococci is due to the production of extracellular proteins and fimbriae.

The role of $S$. oralis and $S$. parasanguis in endodontic infections is not known. However, $S$. oralis posseses surface-associated protein, which helps in its survival (111), and $S$. parasanguis have fimbriae which help it to spread in the bloodstream (1) and survive during wide fluctuations in
$\mathrm{pH}$, temperature, mechanical stress and nutrition $(1,30$, 67).

Polysaccharide producing streptococci like $S$. salivarius, $S$. sanguis and $S$. mutans are less commonly found in the endodontic flora but may possibly enter the root canal during the treatment (10).

\section{Candida}

Yeasts have been recovered in 1-17\% of infected root canals $(4,90,91)$. They comprise less than $1 \%$ of the endodontic flora and are predominantly seen in persistent apical periodontitis $(53,103)$. PCR methods and selective media like Sabouraud dextrose agar and TSBV (Tryptic soy-serumbacitracin-vancomycin) medium are used for detecting yeast. The most important oral yeasts belong to the genus Candida (85). Candida albicans is the most frequently isolated species, followed by C. glabrata, C. krusei, C. tropicalis, C. guilliermondii, C. kefyr and C. parapsilosis (91). The endodontic flora predominantly comprises of $C$. albicans. Candida glabrata, C. guilliermondii, C. inconspicua and Geotrichium candidum are also seen in the root canals (107). Facultative Gram positive bacteria like $\alpha$ and nonhaemolytic Streptococcus species are more commonly associated with each other than with Gram negative species (109). $C$. albicans co-aggregates with $S$. gordonii, $S$. mutans, $S$. sanguis, and this may help in a formation of biofilm $(36,65)$. Candida possesses virulence factors like adherence, hyphae formation, thigmotropism for penetration, protease secretion, and phenotypic switching. $C$. albicans can survive in a nutritionally deprived environment due to the secretion of aspartyl protease and enzymes that can degrade dentinal collagen (107). The Candida, species can also resist the effect of calcium hydroxide. These similarities between enterococci and Candida reveal that both these microbes can endure the environmental conditions within the root canal $(108,109)$.

\section{Actinomyces}

Actinomyces species are grampositive rods and are commonly found in the endodontic flora $(7,96)$. In the root canals of re-treated teeth $A$. israelii has been frequently isolated. A. israelii and A. meyeri have been isolated from teeth with persistent periapical lesion (41). Actinomyces can endure limited availability of nutrients by secreting extra-cellular enzymes that help in the metabolism of sucrose and urea $(16,116)$. The virulence of this species is due to the fimbriae, which also causes extra-radicular endodontic infections (apical actinomycosis) (63). Another explanation for the presence of $A$. israelii in the extra-radicular site may be that $A$. israelii grows as a clump from the canal into the periapical region or it may be pushed into the apical region during endodontic treatment. Actinomyces israelii (56\%) and $A$. gerencseriae ( $25 \%$ ) have been identified in human abscesses. Checkerboard DNA-DNA hybridization analysis 
of root canals with endodontic abscesses have revealed $A$. israelii and $A$. gerencseriae in $14.8 \%$ and $7.4 \%$ of samples, respectively. PCR studies have reported $A$. radicidentis in untreated endodontic infections and root-filled teeth with chronic apical periodontitis. Actinomyces, enterococci, streptococci and Candida are similar in certain aspects such as growth pattern of cohesive filaments or chains, resistance to antimicrobials, growth in monoinfections and evasion of host response (102).

\section{Lactobacillus}

Lactobacillus are Gram positive, non spore forming rods. They have complex nutritional requirements, i.e. fermentative, growing in acidic environment and using sugar. They are identified by whole -cell protein patterns obtained by sodium dodecyl sulfate-polyacrylamide gel electrophoresis (12,43,76), PCR, RAPD-PCR, and system Micro Seq 500 $16 \mathrm{~S}$ rDNA $(81,114)$. The role of Lactobacillus in root canal infection is unknown but can grow in root canals, as they can endure environmental changes. They are regarded as transient contaminants and have been detected in teeth undergoing endodontic treatment and in root-filled teeth with apical periodontitis $(54,99)$. L. uli and L. paracasei were commonly recovered in a study by Chavez de Paz et al. (11). Based on molecular studies $L$. uli has been re-classified to Olsenella uli (21) and is known to produce lactic acid, which can affect the periapical disease process (71). The role of $L$. paracase in root canal infection is unknown. However, its ability to survive in harsh environments may be of importance in endodontic infections (Chávez De Paz et al. unpublished data). Other species like L. acidophilus and $L$. salivarius are rarely isolated from endodontic infections.

\section{Propionibacterium propionicum}

Propionibacterium propionicum is a facultative anaerobe frequently found in intra-radicular and extra-radicular endodontic infection and is recalcitrant to root canal treatment (89). Its pathogenic potential is not exactly known (28) but it is similar to that exhibited by Actinomyces.

\section{Conclusion}

This review on endodontic milieu reveals the complexity of the root canal microflora, the significance of a systematic classification and the role of various microorganism in root canal infection. The recent methods of microbial identification like PCR have opened the floodgates to reveal new taxa and difficult to culture species, which means that the root canal flora is constantly being added to, leading to a better understanding of their role in the root canal disease process. The pathogenic role of numerous microbes are yet unclear. However, a thorough understanding of these complex microbial interactions and their clinical relevance will help in the development of appropriate treatment protocols. Microbial sampling techniques and identification are equally important to recognise and quantify the microbial composition, assess disease progression and devise proper endodontic therapy. Future advances in endodontic microbiology, new therapeutic techniques and a clear understanding of the initiation and progression of the disease process will definitely take us a step closer to the goal of complete microbial elimination for successful root canal treatment.

\section{Acknowledgement}

Thanks are due to doc. MUDr. Věra Hubková, CSc. for her help while preparing this article and to doc. RNDr. Vladimír Buchta, CSc. for his critical appraisal of the review article.

This paper has been supported by the Grant Agency of Ministry of Education, Youth and Physical Training, no. 2B06104.

\section{References}

1. Baddour LM. Virulence factors among gram -positive bacteria in experimental endocarditis. Infect Immun 1994;62:2143-2148.

2. Baumgartner JC, Bae KS, Xia T, Whitt J, David LL. Sodium dodecyl sulfate-polyacrylamide gel electrophoresis and polymerase chain reaction for differentiation of Prevotella intermedia and Prevotella nigrescens. J Endod 1999; 25: 324-328.

3. Baumgartner JC, Falkner WA Jr. Bacteria in the apical $5 \mathrm{~mm}$ of infected root canals. J. Endod 1991;17:380-383.

4. Baumgartner JC, Watts CM, Xia T. Occurrence of Candida albicans in infections of endodontic origin. J Endod 2000; 26:695-698.

5. Bergenholtz G. Micro-organisms from necrotic pulp of traumatized teeth. Odontol Revy 1974;25:347-358.

6. Bergenholtz G, Dahlén G. Advances in the study of endodontic infections: Introduction. Endodontic Topics $2004 ; 9: 1.1-4$.

7. Borssén E,Sundqvist G. Actinomyces of infected dental root canals. Oral Surg Oral Med Oral Pathol 1981;51:643-648.

8. Byström A, Sundqvist G. Bacteriologic evaluation of the efficacy of mechanical root canal instrumentation in endodontic therapy.Scandinavian Journal of Dental Research 1981; 89:321-328.

9. Cavrini F, Sambri V, Moter A et al. Molecular detection of Treponema denticola and Porphyromonas gingivalis in carotid and aortic atheromatous plaques by FISH: report of two cases. Med Microbiol 2005;54: 93-96.

10. Chávez De Paz LE, Dahlén G, Molander A, Moller AJR, Bergenholtz G. Bacteria recovered from teeth with apical periodontitis after antimicrobial endodontic treatment. Int Endod J 2003;36:500-508.

11. Chávez De Paz L. Gram positive organisms in endodontic infections. Endodontic Topics 2004; 9:1,79-96.

12. Chávez De Paz LE, Molander A, Dahlén G. Gram-positive rods prevailing in teeth with apical periodontitis undergoing root canal treatment. Int Endod J 2004:37:579-587.

13. Chávez De Paz LE, Svensater G, Dahlén G, Bergenholtz G. Streptococci from root canals in teeth with apical periodontitis receiving endodontic treatment. Oral Surg Oral Med Oral Pathol Oral Radiol Endod, in press.

14. Choi BK, Lee HJ, Kang JH, Jeong GJ, Min CK, Yoo YJ. Induction of osteoclastogenesis and matrix metalloprotein expression by the lipooligosaccharide of Treponema denticola. Infect Immun 2003;71:226-233.

15. Chung WO, Demuth DR,Lamont RJ. Identification of Porphyromonas gingivalis receptor for the Streptococcus gordonii SspB protein. Infect Immun 2000; 68:6758-6762

16. Clarridge JE III, Zhang Q. Genotypic diversity of clinical Actinomyces species: phenotype, source, and disease correlation among genospecies. J Clin Microbiols 2002;40:3442-3448.

17. Conrads G, Gharbia SE, Gulabivala K, Lampert F, Shah HN. The use of a 16S rDNA directed PCR for the detection of endodontopathogenic bacteria. J Endod 1997; 23:433-438.

18. Cook GS, Costerton JW, Lamont RJ. Biofilm formation by Porphyromonas gingivalis and Streptococcus gordonii. J Periodontal Res 1998;33:323-327. 
19. Curson. History and endodontics. Dental Practitioner and Dental Record. 1965; 15:435-439.

20. Dahlén G, Samuelsson W, Molander A, Reit C. Identification and antimicrobia susceptibility of enterococci isolated from the root canal. Oral Microbiol Immunol 2000;15:309-312.

21. Dewhirst FE, Paster BJ, Tzellas N et al. Characterisation of novel human oral isolates and cloned $16 \mathrm{~S}$ rDNA sequences that fall in the family Coriobacteriaciae: description of Olsenella gen.nov., reclassification of Lactobacillus uli as Olsenella uli comb. nov. and description of Olsenella profusa sp. nov. Int J Syst Evol Microbiol 2001;51:1797-1804

22. El-Sabaeny A, Demuth DR, Park Y, Lamont RJ. Environmental conditions modulate the expression of the sspA and sspB genes in Streptococcus gordonii. Microb Pathog 2000;29:101-113.

23. Evans M, Davies JK, Sundqvist G, Figdor D. Mechanisms involved in the resistance of Enterococcus faecalis to calcium hydroxide. Int Endod J 2002: 35: 221-228.

24. Fabricius L. Oral bacteria and apical periodontitis. An experimental study in monkeys. Thesis, Goteborg University, Gothenburg, Sweden, 1982.

25. Fabricius L, Dahlen G, Holm SE, Moller AJR. Influence of combinations of oral bacteria on periapical tissues of monkeys. Scand J Dent Res 1982:90:200-206.

26. Fabricius L, Dahlen G, Ohman AE, Moller AJR. Predominant indigenous ora bacteria isolated from infected root canals after varied times of closure. Scand J Dent Res 1982;90: 134-144.

27. Fenno JC, McBride BC. Virulence factors of oral treponemes. Anaerobe 1998; 4:1-17.

28. Figdor D, Sjogren U, Sorlin S,Sundqvist G, Nair PNR.Pathogenecity of Actinomyces israelii and Arachnia propionica: experimental infection in guinea pig and phagocytosis and intracellular killing by human polymorphonuclear leukocytes in vitro. Oral Microbiol Immunol 1992;7:129-136.

29. Foschi F., Cavrini F., Montebugnoli L., Stashenko P., Sambri V., Prati C. Detection of bacteria in endodontic samples by polymerase chain reaction assays and association with defined clinical signs in Italián patients. Oral Microbio Immunol 2005;20:1-8.

30. Froeliger EH, Fives- Taylor P. Streptococcus parasanguis fimbria-associated adhesin fap1 is required for biofilm formation. Infect Immun 2001;69:2512-2519.

31. Gomes B. P. F. A., Jacinto R. C., Pinheiro E. T. et al. Porphyromonas gingivalis, Porphyromonas endodontalis, Prevotella intermedia and Prevotella nigrescens in endodontic lesions detected by culture and by PCR. Endodontic Topics 20:4,1-8

32. Gomes BP, Lilley JD, Drucker DB. Variations in the susceptibilities of components of the endodontic microflora to biomechanical procedures. Int Endod J 1996;29:235-241.

33. Gomes BPFA, Pinheiro ET, Gade- Neto CR et al. Microbiological examination of infected dental root canals. Oral Microbiol Immunol 2004;19:71-76.

34. Haapasalo M, Ranta H, Ranta K, Shah H. Black-pigmented Bacteroides spp. in human apical periodontitis. Infect Immun 1986;53:149-153.

35. Haffajee AD, Cugni MA, Tanner A et al. Subgingival microbiota in healthy, well maintained elder and periodontitis subjects. J. Clin Periodontol 1998;25: 346-353.

36. Holmes AR, Cannon RD, Jenkinson HF. Interactions of Candida albicans with bacteria and salivary molecules in oral biofilms. J Ind Microbiol 1995;15: 208-213.

37. Hubble TS, Hatton JF, Nallapareddy SR, Murray BE, Gillespie MJ. Influence of Enterococcus faecalis proteases and the collagen-binding protein, Ace, on adhesion to dentin. Oral Microbiol Immunol 2003;18: 121-60.

38. Huebner J, Wang Y, Krueger WA. et al. Isolation and chemical characterization of a capsular polysaccharide antigen shared by clinical isolates of Enterococcus faecalis and vancomycin-resistant Enterococcus faecium. Infect Immun 1999; 67 1213-1219.

39. Jansen H-J. The periodontal microflora as a protein-dependent anaerobic degradation system. Department of Preventative Dentistry and Periodontology, University of Nijmegen, the Netherlands, 1996.

40. Kakehashi S, Stanley HR,Fitzgerald RJ. The effects of surgical exposures of dental pulps in germ-free and conventional laboratory rats. Oral Sur, Oral Med, Ora Pathol 1965:20:340-349.

41. Kalfas S, Figdor D, Sundqvist G. A new bacterial species associated with failed endodontic treatment: identification and description of Actinomyces radicidentis. Oral Surg Oral Med Oral Pathol Oral Radiol Endod 2001;92: 208-214

42. Kantz WE, Henry CA. Isolation and classification of anaerobic bacteria from intact pulp chambers of non-vital teeth in man. Archs Oral Biol 1974;19:91-96.

43. Kersters K, De Ley J. Identification and grouping of bacteria by numerical analysis of their electrophoretic protein patterns. J Gen Microbiol 1975; 87: 333-342.

44. Lamont RJ, El -Sabaeny A, Park Y, Cook GS, Costerton JW, Demuth DR. Role of the Streptococcus gordonii SspB protein in the development of Porphyromonas gingivalis biofilms on streptococcal substrates. Microbiology 2002;148 $1627-1636$

45. Lana MA, Ribeiro-Sobrinho AP, Stehling R et al. Microorganisms isolated from root canals presenting necrotic pulp and their drug susceptibility in vitro. Oral Microbiol Immunol 2001;16:100-105.
46. Love R. Invasion of dentinal tubules by root canal bacteria. Endod Topics 2004 ;9:52-65.

47. Love RM, McMilan MD, Park Y, Jenkinson HF. Coinvasion of dentinal tubules by Porphyromonas gingivalis and Streptococcus gordonii depends on the binding specificity of streptococcal antigen I/II adhesin. Infect Immun 2000; 68: $1359-1365$

48. Makinen P-L, Clewell DB, An F, Makinen KK. Purification and substráte specificity of a strongly hydrophobic extracellular endopeptidase ('gelatinas') from Streptococcus faecalis (strain 0G1-10). J Bio Chem 1989; 264: 3325-3334.

49. Miller WD. An introduction to the study of the bacterio-pathology of the dental pulp. Dent Cosmos 1894; 36:505 -527.

50. Mims C, Dimmock N, Nash A, Stephen J. Mim's Pathogenesis of Infectious Diseases. New York:Academic Press 1995.

51. Molander A, Dahlén G. Evaluation of the antibacterial potential of tetracycline or erythromycin mixed with calcium hydroxide as intra canal dressing against Enterococcus faecalis in vivo. Oral Surg Oral Med Oral Pathol Oral Radiol Endod 2003;96:744-750

52. Molander A, Reit C, Dahlén G. The antimicrobial effect of calcium hydroxide in root canals pretreated with 5\% iodine potassium iodide. Endod Dent Traumatol 1999; 15:205-209.

53. Molander A, Reit C, Dahlén G, Kvist T. Microbiological status of root- filled teeth with apical periodontitis. Int Endod J 1998;31:1-7.

54. Moller AJR. Microbiological examination of root canals and periapical tissues of human teeth. Methodological studies. Odontol Tidskr 1966; 74(Suppl):1-380.

55. Moller AJR, Fabricius L, Dahlén G, Sundqvist G, Happonen RP. Apical periodontitis development and bacterial response to endodontic treatment. Experimental root canal infections in monkeys with selected bacterial strain. Eur J Oral Sci 2004;112:207-215.

56. Moore LV, Johnson JL, Moore WE. Descriptions of Prevotella tannerae sp. nov. and Prevotella enoeca sp. nov. from the human gingival crevice and emendation of the description of Prevotella zoogleoformans. Int J Syst Bacteriol 1994;44: 599-602.

57. Moore WEC, Moore LVH. The bacteria of periodontal diseases. Periodonto 2000 1994;5: 66-77.

58. Mullis KB, Faloona FA. Specific synthesis of DNA in vitro via a polymerase - catalysed chain reaction. Meth Enzymol 1987;155:335-350.

59. Mundy LM, Sahm DF, Gilmore M. Relationships between enterococcal virulence and antimicrobial resistance. Clin Microbiol Rev 2000;13:513-522.

60. Munson MA, Pitt-Ford T, Chong B, Weightman A, Wade WG. Molecular and cultural analysis of the microflora associated with endodontic infections. J Dent Res 2002;81:761-766 (Erratum in: J Dent Res 2003;82:69. J Dent Res 2003;82: 247).

61. Muyzer G, de Waal EC, Uitterlinden AG. Profiling of complex microbial populations by denaturing gradient gel electrophoresis analysis of polymerase chain reaction -amplified genes coding for 16S rRNA. Appl Environ Microbiol 1993; 59:695-700.

62. Muyzer G, Smalla K. Application of denaturing gradient gel electrophoresis (DGGE) and temperature gradient gel electrophoresis (TGGE) in microbial ecology. Antonie van Leeuwenhoek 1998;73:127-141.

63. Nair PNR, Schroeder HE. Periapical actinomycosis. J Endod 1984;10:567-570.

64. Nallapareddy SR, Singh KV, Duh RW, Weinstock GM, Murray BE. Diversity of ace, a gene encoding a microbial surface component recognizing adhesive matrix molecules, from different strains of Enterococcus faecalis and evidence for production of ace during human infections. Infect Immun 2000;68:5210-5217.

65. Nikawa H, Egusa H, Makihira S. et al. Alteration of the coadherence of Candida albicans with oral bacteria by dietary sugars. Oral Microbiol Immunol 2001;16:279-283.

66. Nonaka E, Kiyama-Kishikawa M,Hayakawa M. Identification of 40-k Da outer membrane protein as an aggregation factor of Porphyromonas gingivalis to Streptococcus gordonii. J Oral Sci 2001;43:239-243.

67. Odds FC. Candida and candidosis-a review and bibliography. 2nd ed. London: Bailliére Tindall-W.B. Saunders, 1988

68. Oetjen J, Fives-Taylor P, Froeliger EH. The divergently transcribed Streptococcus parasanguis virulence -associated fimA operon encoding an $\mathrm{Mn}(2+)$-responsive metal transporter and pepO encoding a zinc metallopeptidase are not coordinately regulated. Infect Immun ;70:5706-5714.

69. Olmsted SB, Dunny GM, Erlandsen SL, Wells CL. A plasmid-encoded surface protein on Enterococcus faecalis augments its internalization by cultured intestinal epithelial cells. J Infect Dis 1994; 170: 1549-1556.

70. Olsen GJ,Woese CR,Overbeek LV. The winds of evolutionary change: breathing new life in microbiology. J Bacteriol $1994 ; 176: 1-6$

71. Olsen I, Johnson JL, Moore LV, Moore WE. Lactobacillus uli sp. nov. and Lactobacillus rimae sp. nov. from the human gingival crevice and emended descriptions of Lactobacillus minutus and Streptococcus parvulus. Int J Sys Bacteriol 1991;41:261-266

72. Orstavik D, Haapasalo M. Disinfection by endodontic irrigants and dressings of experimentally infected dentinal tubules. Endod Dent Traumatol 1990;6: 142-149.

73. Paster BJ, Boches SK, Galvin JL et al. Bacterial diversity in human subgingival plaque. J Bacteriol 2001;183:3770-3783. 
74. Pitt Ford T. R. Harty $s$ Endodontics in Clinical Practice $4^{\text {th }}$ edition, pp. 1-3

75. Polz MF, Cavanaugh CM. Bias in template - to- product ratios in multitemplate PCR. Appl Environ Microbiol 1998;64:3724-3730.

76. Pot B, Hertel C, Ludwig W, Descheemaeker P, Kersters K, Schleifer KH Identification and classification of Lactobacillus acidophilus, L. gasseri and $L$. johnsonii strains by SDS-PAGE and rRNA-targeted oligonucleotide probe hybridisation. J Gen Microbiol 1993;139 (part 3):513-517.

77. Rakita RM, Vanek NN, Jacques-Palaz K et al. Enterococcus faecalis bearing ag gregation substance is resistant to killing by human neutrophils despite phagocytosis and neutrophil activation. Infect Immun 1999;67:6067-6075.

78. Reit C, Dahlén G. Decision making analysis of endodontic treatment strategies in teeth with apical periodontitis. Int Endod J 1998;21:291-299.

79. Reysenbach AL, Giver GS,Wickham GS, Pace NR. Differential amplification of rRNA genes by polymerase chain reaction. J. Clin Microbiol 1992;58: 3417-3418.

80. Rudney JD, Chen R, Pan Y. Endpoint quantitative PCR assays for Bacteroides forsythus, Porphyromonas gingivalis and Actinobacillus actinomycetemcomitans. J. Periodontol Res 2003:38:465-470.

81. Schillinger U, Yousif NM, Sesar L, Franz CM. Use of group- specific and RAPDPCR analyses for rapid differentiation of Lactobacillus strains from probiotic yoghurts. Curr Microbiol 2003;47:453-456.

82. Schlievert PM, Gahr PJ, Assimacopoulos AP et al. Aggregation and binding sub stances enhance pathogenicity in rabbit models of Enterococcus faecalis endocarditis. Infect Immun 1998;66:218-223.

83. Sedgely C, Clawell D. Bacterial plasmids in the oral and endodontic microflora Endod Topics 2004;9:37-51

84. Shankar N, Lockatell CV, Baghdayan AS, Drachenberg C, Gilmore MS, Johnson DE. Role of Enterococcus faecalis surface protein Esp in the pathogenesis of ascending urinary tract infection. Infect Immun 2001;69:4366-4372.

85. Siren EK, Haapasalo MP, Ranta K, Salmi P, Kerosuo EN. Microbiological findings and clinical treatment procedures in endodontic cases selected for microbiological investigation. Int Endod J 1997;30:91-95.

86. Siqueira JF Jr, Rocas IN, Helio P. Lopes. Patterns of microbial colonisation in primary root canal infections. Oral Surg Oral Med Oral Pathol Oral Radiol Endod 2002:93:174-178.

87. Siqueira JF Jr, Rocas IN, Oliveira JCM, Santos KRN. Molecular detection of black-pigmented bacteria in infections of endodontic origin. J Endod 2001; 27:563-566.

88. Siqueira JF Jr, Rocas IN,Rosado AS. Investigation of bacterial communities associated with asymptomatic and symptomatic endodontic infections by denaturing gradient gel electrophoresis fingerprinting approach. Oral Microbiol Immunol 2004:19:363-370

89. Sjogren U, Happonen RP, Kahnberg KE, Sundqvist G. Survival of Arachnia propionica in periapical tissue. Int Endod J 1988;21:277-282.

90. Slack G. The bacteriology of infected root canals and in vitro penicillin sensitivity. Br Dent J 1953;3:211-214.

91. Slack G. The resistance to antibiotics of microorganisms isolated from root canals. Br Dent J 1957;18:493-494.

92. Socransky SS, Haffajee AD, Cugni MA, Smith C, Kent RL. Microbial complexes in subgingival plaque. J. Clin Periodontol 1998;25:134-144.

93. Socransky SS, Smith C, Martin L, Paster BJ, Dewhirst FE, Levin AE. Checkerboard DNA-DNA hybridization. Biotechnique 1994;17:788-792.

94. Spratt DA. Significance of bacterial identification by molecular biology methods. Endodontic Topics 2004;9:1-11.
95. Sundqvist G. Associations between microbial species in dental root canal infections. Oral Microbiol Immunol 1992;7:257-262.

96. Sundqvist G. Bacteriological studies of necrotic dental pulps. Odontological Dissertations. Umea, Sweden:Umea University,1976.

97. Sundqvist G. Endodontic microbiology. In: Spangberg LSW, ed.Experimental Endodontics, Vol.6. Boca Raton: CRC Press, 1990; 131-153.

98. Sundqvist G. Taxonomy, ecology, and pathogenicity of the root canal flora. Oral Surg Oral Med Oral Pathol 1994 Oct; 78(4):522-530.

99. Sundqvist $\mathrm{G}$, Carlsson J. Lactobacilli of infected dental root canals. Odonto Revy 1974;25:233-238.

100. Sundqvist G, Carlsson J, Herrmann B, Tärnvik A. Degradation of human immunoglobulins $\mathrm{G}$ and $\mathrm{M}$ and complement factors $\mathrm{C} 3$ and $\mathrm{C} 5$ by black-pigmented Bacteroides. J Med Microbiol 1985;19:85-94.

101. Sundqvist G, Eckerbom MI, Larsson AP, Sjogren UT. Capacity of anaerobic bacteria from necrotic dental pulps to induce purulent infections. Infect Immun 1979;25:685-93.

102. Sundqvist $\mathrm{G}$ and Figdor D. Life as an endodontic pathogen. Endodontic Topics 2003;6:1-25

103. Sundqvist G, Figdor D, Persson S, Sjogren U. Microbiologic analysis of teeth with failed endodontic treatment and the outcome of conservative re-treatment. Oral Surg Oral Med Oral Pathol Oral Radiol Endod 1998;85:86-93.

104. Svensater G, Bergenholtz G. Biofilms in endodontic infections. Endodontic Topics 2004;9:27-36

105. Tanner A, Kent R, Maiden MFJ, Taubman MA. Clinical microbiological and immunological profile of healthy, gingivitis and putative active periodontal subjects. J. Periodontol Res 1996;31:195-204.

106. van Winkelhoff AJ, Carlee AW, de Graaff J. Bacteriodes endodontalis and other black-pigmented Bacteroides species in odontogenic abscesses. Infect Immun 1985;49:494-497.

107. Waltimo TM, Haapasalo M, Zehnder M, Meyer J. Clinical aspects related to endodontic trast infections. Endodontic Topics 9;1-13.

108. Waltimo TM, Sen BH, Meurman JH, Orstavik D, Haapasalo MP. Yeasts in apical periodontitis. Crit Rev Oral Biol Med 2003;14:128-137.

109. Waltimo TM, Sirén EK, Torkko HL, Olsen I, Haapasalo MP. Fungi in therapyresistant apical periodontitis. Int Endod J 1997; 30: 96-101.

110. Wasfy MO, McMahon KT, Minah GE, Falkler WA Jr. Microbiological evaluation of periapical infections in Egypt. Oral Microbiol Immunol 1992;7:100-105.

111. Wilkins JC, Beighton D, Homer KA. Effect of acidic $\mathrm{pH}$ on expression of surface-associated proteins of Streptococcus oralis. Appl Environ Microbiol 2003;69:5290-5296

112. Wilson MJ, Weightman AJ, Wade WG. Applications of molecular ecology in the characterisation of uncultured microorganisms associated with human disease. Rev Med Microbiol 1997; 8: 91-101.

113. Wittgow WC Jr, Sabiston CB Jr. Microorganisms from pulp chambers of intact teeth necrotic pulps. J Endod 1975;1:168-171.

114. Woo PC, Ng KH, Lau SK et al. Usefulness of the MicroSeq 500 16S ribosomal DNA-based bacterial identification system for identification of clinically significant bacterial isolates with ambiguous biochemical profiles. J Clin Microbiol 2003;41:1996-2001

115. Wyss C. Dependence of proliferation of Bacteroides forsythus on exogenous N-acetylmuramic acid. Infect Immun 1989;57:1757-1759.

116. Yeung MK. Molecular and genetic analysis of Actinomyces spp. Crit Rev Ora Biol Med 1999;10:120-138.

\section{Corresponding author:}

MUDr. Romana Ivančaková, CSc., University Hospital Hradec Králové, Department of Dentistry, Sokolská 581, 50005 Hradec Králové, Czech Republic, e-mail: ivancakovar@lfhk.cuni.cz 